\title{
Consequences of Realism for Sociological Theory-Building
}

\section{THOMAS BRANTE}

Just don't get too complicated, Eddie /Sociology/. When a man gets too complicated, he is unhappy. And when he is unhappy, his luck runs out.

Raymond Chandler

Sociologists have again started meta-theoretical debates about their discipline in terms of crisis, fundamental goals and purposes, cores and identities. ${ }^{1}$ It is nowadays frequently claimed that internally, the subject is becoming far too fragmented while externally, the demand for sociological knowledge is decreasing. Internally, the discipline is marked by what Donald Levine (1997: 1) calls "pluralistic confusion." Irving Horowitz holds that "sociology has degenerated into pure empiricism, no longer guided by worthwhile theoretical perspectives" (Giddens 1996: 2). In Sweden Göran Ahrne (1997: 275) claims that "In sociology there is a process of fragmentation concerning theories and methods as well as objects of study" and in Norway Fredrik Engelstad (1996: 225) writes that sociology is "squeezed between political commitments on the one hand, and seductive pseudo-philosophy on the other". In England, Nicos Mouzelis (1995: 6) laments that "sociological theorizing gave way to amateur discussions on ontological/epistemological issues, and to attempts at reducing the study of complex societies to that of language, discourse, texts, the unconscious and suchlike." Barry Barnes (1995: 1) reports the complaint that what now exists as sociological theory is "ersatz theory, a substitute for theory, a hotchpotch of critique, philosophy, taxonomy, history, the biography of theorists, practically anything, in fact, save theory itself."

So internally, sociology is becoming increasingly fragmented. Now this spectrum of directions can of course be appreciated as something fruitful and interesting, a sign that the subject is really alive and kicking, but also as regrettable, even depressing, since the possible identity of the subject seems to dissolve. Here I will take the second view and see the fragmentation of sociology as a problem. As concerns both problem and possible solutions, I have two convictions: 
1. Sociology badly needs a new philosophy of science that can help stabilizing it, especially by providing a common platform and a shared general goal for its practitioners.

2. The Achilles heel of contemporary sociology is its weak theoretical development; consequently the subject must be strengthened as regards sociological theory (and not merely theory borrowed from other subjects). ${ }^{2}$ Sociology must seek to be an explanatory science, implying a deepening of its own theoretical knowledge. A corollary belief is that a crucial preparation for improving theory development is theoretical elaboration of the object of sociology. By the object of sociology I refer to delineation and definition of the reality a sociological theory purports to explain, which is not the same as spontaneously observed reality but rather specific objects of knowledge, or models. ${ }^{3}$

In the following I will take a step back and start with a few remarks about the current relationship between sociology and the philosophies of science. Thereafter I present an alternative philosophy or meta-theory for sociology, which is based on critical realism but will here be called "causal realism"; causal realism can be seen as a sub-category of critical realism, see further below. In the following main part, I outline and discuss some implications of causal realism to sociology. In particular, a strategy for raising the ambitions of sociological theory-development is presented.

I also want to mention that originally, the idea of this paper was to try to present one consistent line of thought and refrain from going into details, anticipate possible objections, and so forth. (To paraphrase Nietzsche: here I philosophize with an ax, not with tweezers.) However, some discussions of my topic have taught me that this is almost impossible; standard objections invariably creep up, diverting focus from the main issues. Therefore, this paper has a rather perverse amount of endnotes where I reflect upon at least some critical comments. Perhaps I should also mention that "nothing new" is presented below; rather, guided by the two convictions stated above, I rearrange some old puzzle pieces.

\section{PHILOSOPHIES OF SCIENCE AND SOCIOLOGY}

A philosophy of science constitutes a superstructure to a specific science, a theoretical framework through which the science in question is perceived and understood, and by which scientific criteria are formulated. A theoretical structure is both constraining and enabling. It points out what is scientific and what is not, what counts as legitimate methods, proper modes of solution, relevant problems, and so forth - in brief, it presents a number of criteria, rules, demands and ways of procedure. Further, and to use Imre Lakatos' terms, during one phase a philosophy of science can exert a progressive influence but later turn into having stagnating or even degenerative effects on a given discipline. 
Logical positivism as formulated by the Vienna Circle during the 1920's constituted a powerful reaction to neo-romanticism and the too loose speculations of the $19^{\text {th }}$ century, often Hegel-inspired. As a contrast to metaphysical speculation, it emphasized certainty and empirical verifiability. In this sense positivism was progressive, simultaneously constraining the scope of scientific discourse and opening a rigorous field of possibility by insisting on empirical anchorage. During the latter part of our century, however, positivism in social science has come to be equalized with observability, quantification, and measurement, often "for its own sake." To be scientific has become tantamount to constraining oneself to a certain method according to which statistics and advanced computer treatment often assumes a value of its own. (Indeed, the focus on measurement and numbers advanced by Hume, Kelvin and other early "anti-metaphysicists" seems to have been transformed into a new social-scientific doctrine. For instance, Hume's (1748/1999: 173): "Does it contain any abstract reasoning concerning quantity or number? No . . Commit it then to the flames" seems to have changed into "If you cannot measure, measure anyhow.") One major reason for this development is the advancement of sophisticated statistical computer programs, turning quantitative methodology into a branch of statistics. The result is, as Aage Sörenssen (1998: 238) points out, that "quantitative sociology is now less theoretically informed and less relevant for theoretical progress than it was three decades ago." Paradoxically, then, the anti-metaphysical or positivistic ambition to be scientific has sometimes engendered its opposite.

The critique of positivism launched in the 1960s can be explained in many ways, e.g. socio-politically, but the critique also indicates that in several areas, positivism had changed from a progressive to a dogmatic, stagnating meta-theory. The anti-positivist reactions sought to liberate the sciences from stereotypes about a neutral and objective observational basis in order to enable theories that "produced" new types of observations, in social science as well as in quantum physics. The results of Thomas Kuhn's and especially Paul Feyerabend's critique of positivism and critical rationalism, also empiricist, were transformed into extremely relativist philosophies of science that were sometimes interpreted to imply that anything goes, that it is possible to "let a hundred flowers bloom." ${ }^{4}$ In sociology, relativism during the 70 s gave rise to a large number of paradigm candidates, often based upon subjects adjacent to sociology like linguistics, semiotics, psychoanalysis, politics, and literature.

Although lots has happened since the $70 \mathrm{~s}$, these two traditions - what I here without much further qualification will summarize as positivism and a set of epistemological relativisms - continue to dominate the sociological arena, constituting opposing poles in the seemingly endless discussions about the nature and purpose of sociology. Positivism has evolved into what Dag Österberg (1988) calls "social statistics", which he claims should be separated from a sociology with explanatory ambitions. Relativism has resulted in post-modernism, poststructuralism, social constructivism, discourse analysis, linguistic and cultural 
turns. ${ }^{5}$ Common to the latter is the denial of scientific criteria and sometimes also that scientific conceptual systems have any reference to external reality whatsoever. In these cases, science is understood as discourses involving concepts the objects of which do not exist or are constructed in the scientific process; the referent is merely one more reified construction.

When this is said it should also be admitted that it is very difficult to pinpoint what "positivism" and "ultra-relativism" actually stands for; both these -isms are characteristically vague. ${ }^{6}$ To my mind, however, ultra-relativism can in many respects be understood as a reaction to, even the other side of the coin of, positivism. Methodologically, we have one the one hand empirical variable analysis and a general emphasis on quantitative methodology, on the other discourse analysis, narrative, and a general emphasis on qualitative methods. Both provide highly constraining rules; one the one hand, non-observable entities are forbidden, on the other, all accounts of the social must be based on, for instance, the intentions of the acting subjects. Epistemologically, while one side sharply demarcates scientific knowledge from other forms of knowledge, the other denies the existence and possibility of demarcations; while one underscores the superiority of science, the other underscores the relativity and indeed the equality of all knowledge claims. Ontologically, while one side is phenomenalist, the other tends towards idealism. Politically, the early positivists as well as modern relativists saw or see themselves as radical, which can be questioned. Nowadays at least, positivism is frequently associated with elitism and ethnocentrism, and relativism's denial of the possibility of superior knowledge seems to undercut the possibility of rational societal critique, turning us back to the old "might is right." In his last book, Feyerabend (1995: 152) is explicit about these two strands: "Objectivism and relativism not only are untenable as philosophies, they are bad guides for a fruitful cultural collaboration."

\section{META-THEORETICAL REQUIREMENTS}

To my mind, then, nowadays positivism as well as ultra-relativism have degenerative implications for the development of sociology. It should also be noted that both positivism and ultra-relativism get inspiration from sciences and philosophies outside of sociology proper; on the one hand from a conception of natural science (that, incidentally, is completely misinformed), on the other hand from neoKantian or Diltheyan or poststructuralist philosophy. However, it is high time that sociology takes itself seriously and sets out from its own knowledge and needs. Sociology has reached a maturity empowering it to stand on its own feet and its knowledge be granted a certain autonomy. We need a conception of sociology as science that does not hamper the research process and sociological imagination and yet promotes a reasonably common effort towards certain general and shared goals, i.e. a theoretical superstructure facilitating cumulative 
research. This need is not lived up to by extant philosophies of science. Hence the term "meta-theory", which stands in between a general philosophy of many sciences and a particular science. What needs should such a superstructure of sociology fulfill? I think the following three requirements are crucial:

1. A meta-theory should be as simple and straightforward as possible, without therefore being unsophisticated. By "not unsophisticated" I mean that it must take due notice of the most basic findings in philosophy of science, such as the thesis of the theory-dependence of facts, the existence of paradigms, that there are no absolute criteria of theory choice or truth, and link these to the conditions and needs of the empirical discipline. "Simple" or straight-forward implies that a sociological meta-theory should not lead to years of cumbersome philosophical studies but rather constitute a platform guiding researchers towards the essential goal of their discipline (see below). Sociology is an intellectual discipline and must indeed remain so, but basically in its own domain - too much diversification implies too much complexity, and the subject will "run out of luck."

2. A meta-theory for sociology must, in view of the present fragmented status of the subject, remain agnostic in regards to single theories and methods; that is, it must advocate theoretical and methodical pluralism. At the same time, it must be able to point out general conditions and objectives for the subject, regardless of specific theories and methods.

3. A meta-theory should emphasize that sociological research must be of both disciplinary and social relevance. We can imagine these two demands as poles in a continuum. Research lacking social relevance deals with internal, esoteric puzzles. Of course, such kind of research is sometimes also crucial, but mainstream sociology should concern issues of social and political relevance. The opposite, no disciplinary relevance, can be exemplified by public reports or politically significant articles written by sociologists in which no sociological competence is discernible; the report could have been written by anyone. The main part of sociological studies should seek to find an optimal balance between these two poles.

\section{GAUSAL REALISM}

Let me now offer a simple outline of what I call "causal realism." The label seeks to distinguish this alternative from other meta-theories with labels like naive realism, empirical realism, scientific realism, neo-realism, critical realism, and others. Although there are clear influences from in particular critical realism, the proposed alternative is different. ${ }^{7} \mathrm{I}$ begin by stating the general points of departure of causal realism. Thereafter I take up three of its core concepts: causality, 
mechanism, and stratified reality. ${ }^{8}$ Finally, I sketch some consequences concerning how sociology should be conceived and which sociological research areas come out as the most important, according to this meta-theory and these concepts.

The postulates of causal realism

The philosophical debates about various forms of realism (or materialism) and idealism appear perpetual, and there are indeed no obvious philosophical or other methods to terminate them. I will not dive into this squirrel's wheel but instead state the three postulates or axioms of causal realism:

1. There is a reality existing independently of our representations or awareness of it (ontological postulate).

la. There is a social reality existing independently of social scientists' representations or awareness of it (ontological postulate for social science).

2. It is possible to achieve knowledge about this reality (epistemological postulate).

3. All knowledge is fallible - and correctable (methodological postulate).

I will come back to the consequences of these postulates for sociology. For now it should be noted that postulate 1 serves to put an end to general discussions regarding whether society really exists, if it exists only in the human mind, and so forth. However, the postulate does not imply that only "the material" exists. It suffices to recall Durkheim's social facts. Social reality is material and mental. Postulate 2 puts an end to questions about the general possibility of sociology, affirming or taking for granted that scholars like Marx, Weber, Durkheim and so on up to our days really do say something about their objects of study; genuine sociological knowledge exists. Postulate 3 seeks to take seriously the achievements made in philosophy of science during the latest decades; again, under-determination, theory-dependence, no truth-absolute criteria, paradigms, and so forth. Postulate 3 also implies that scientific concepts may be constructed in the sense of having no real, external referent. However, the question of reference is not a principal or a philosophical issue that can be resolved a priori, as many proponents of social constructivism seem to believe. On the contrary, it is something that has to be carefully empirically investigated in each case.

\section{CAUSALITY}

The simplest answer to the question of the ultimate purpose of science is that it seeks to provide causal explanations of effects. The effects may be virtually anything and concern phenomena like the sun goes down beyond the horizon, stones fall 
to the ground, social groups cooperate or compete, people get ill, are happy, or what have you. Explanations may be of many different kinds, from complicated mathematical equations to simple assertions that a certain event preceded a certain effect.

This statement may seem self-evident but is in fact quite controversial in sociology. The reason for its controversiality stems from previous philosophies of science. (Indeed, from a common-sense point of view, one of the most remarkable ideas in traditional and modern philosophy of science must be positivism's and phenomenology's mutual denial of the ordinary concept of causality.) Positivism's concept of cause - the theory of regularity - has evolved from David Hume's well-known treatise, defining causality as associations between observable phenomena, as expressed in the familiar formula: a phenomenon $\mathrm{A}$ is called cause to a phenomenon $\mathrm{B}$ if and only if $\mathrm{A}$ and $\mathrm{B}$ are connected in time and space, A occurs before $\mathrm{B}$, and there is a constant conjunction between cause and effect, A and B. To sociology this has implied - especially during the present time of large computer programs - that causal analysis is tantamount to co-variation between quantified variables, i.e. to establish to what extent variation in $\mathrm{A}$ $(\mathrm{C}, \mathrm{D}, \mathrm{E} \ldots \mathrm{i})$ give raise to variation in B. This conception of causality is, first, dubious for purely theoretical reasons, second, it ties sociology to a very limited concept of causality, and third, there are completely plausible alternative causal conceptions (Ekström 1994).

Moreover, defining causality as regularities between observable phenomena entails that classic and large parts of contemporary sociology must be rejected. Marx, Weber, Durkheim, Parsons and so forth all worked with non-observable entities generating observable effects. Marx' notion of specific relations of production or Freud's notion about the unconscious sought to signify structures involving causal mechanisms. My point is that either we must discard the larger part of sociological knowledge or else broaden the concept of causality. Im passim, it may be noted that given the positivist concept of causality a very large part of natural science must also be rejected, such as the law of gravity and the theory of natural selection. Both theories refer to non-observable entities generating observable effects. Moreover, to my mind even sociological classics that are normally not associated with causal analysis implicitly work with causal models. For instance, Foucault's "geneaology", his analyses of the histories of madness, knowledge, punishment, or sexuality, are basically nothing but original attempts to identify sets of often very broad historical structures that gave rise to sets of specific phenomena. Beyond Foucault's mode of presentation there are causal models that are possible and quite easy to explicate.

Hence, the alternative notion advocated here conceives causality in a more tolerant and "enabling" manner. In this limited space it would carry too far to go into a detailed discussion, but let me state the following. First, causality should not be defined as law-like universal regularities between observables A and $\mathrm{B}$. We can let this definition be a pole in a continuum where the other pole 
involves something like "in certain circumstances, it is likely that B will occur", i.e. a causal relation that holds sometimes. The first form of causality occurs almost exclusively in physics, other sciences have few or no laws of universal validity. As Clark Glymour (1983: 127) points out, the bulk of science consists of causal explanations without laws. Second, in practice causality occur as tendencies, partly because causalities can counteract, entailing that expected effects or net-effects are not necessarily manifested in empirically observable effects. For instance, a company seeking rationalizations may be counteracted by a strong labor union. The human body is constantly attacked by numerous harmful bacteria that are normally counteracted by the immune system. The tendencies exist even though the effects are nullified. The general basis for understanding causality and probability in this way is neatly summarized by Karl Popper (1990) as "a world of propensities." Third, especially in the social sciences we should admit the concept "causal capacity" as a referent to a disposition or liability of an object or actor. A bomb has the disposition or power to explode. A human being that works constitutes a causal power. If she is unemployed and does not work this does not mean that she does not possess the latent causal capacity of working (Sayer 1992). Inner capacity plus external situation explains propensity. Fourth, presumably due to the extant positivistic conception of causality as constant conjunction, sociological texts are replete with "sensitizing" connecting terms like "influences", "affects", "hangs together with", "is correlated to". However, such terms should not be regarded as solutions to be left but rather as indications of problems to be further examined. Higher ambitions and a more straightforward terminology, deploying "bolder" terms like "cause", would help sharpening concentration and focus on the nature of connections.

Thus, causality is intimately connected with understanding ${ }^{9}$ and explanation. An observed regularity, for instance that juveniles from lower social groups to a lesser extent proceed to higher education, or that women receive lesser salaries than men for the same job, in both cases in spite of formal equality, are as such no explanations. In order to understand regularities of these and similar kinds it is necessary to identify the social mechanisms that preserve real inequality. Most often this implies going beyond the surface of regularity, employing other methods than statistics to analyze components that may account for the phenomenon we are interested in. As Nancy Cartwright (1983: 10) expresses it: "If only laws of association are admitted, the length of the shadow can as well explain the height of the flagpole as the reverse."

To summarize this summary: instead of departing from a constraining positivist philosophy of causality implying skepticism and doubt it may be more suitable to set out from postulate 2 above. This means that we acknowledge that sociology is indeed capable of obtaining and expressing genuine knowledge of social reality and then ask ourselves: if this is the case, what kind of world, what kind of causality, and what explanatory instruments must exist? We commence from sociology's own knowledge, not from philosophical principles. And this means 
that sociology should not deprive itself of the concept of causality because of the positivistic definition; positivism has no monopoly on this concept. On the contrary sociology should accept causal relations such as structural causality, expressive causality, reciprocal causality, causal feedback loops, intentional causality, functional causality, and so forth. Indeed, if we want to be able to continue reflecting upon sociology as a science, traditional concepts like causality, mechanism, explanation, cumulativity and the like are, duly redefined, indispensable.

Ontologically, this position implies that not only observation but also causal capacity is a criterion of existence, which is one major reason for the label causal realism.

\section{MECHANISMS $^{10}$}

Reality encompasses infinite amounts of causal processes. Science-be it natural or social-have no possibilities and no ambitions to describe or explain all of these. No natural science can predict where a leaf, carried away by the autumn winds, will fall. And as the chaos theorists stress: the movements of a butterfly in China may cause rain in Lisbon. The natural sciences do not have this ambition but seek to identify the basic and durable mechanisms upon which surface phenomena rely. In the social sciences, we have the same situation. A person going for a walk in a city is influenced by myriads of factors - cars to be avoided, shop windows generating thoughts, other people to chat with. The task of sociology cannot be describing this myriad but, analogous to natural science, to identify the relatively enduring structures and mechanisms that to a greater or lesser extent produce surface phenomena, and that is exactly what we find in e.g. Goffman's analyses of social interaction, for instance the mechanisms governing typical behavior at street encounters.

Mechanisms are embedded in structures, they are "structurally dependent." A structure is a comparatively durable configuration of elements. A specific configuration of elements implies that some events are possible, plausible or necessary while others are impossible or implausible. In the case of natural science, we can say that a mechanism is what a natural law is based upon and concerns. The mechanism of "attraction" is the base for the law of gravity. In social science, a mechanism may be what a statistical association is based upon. If we have found that longer and harder criminal punishment results in increased dispositions to crime after time is served, the mechanism or mechanisms are the conditions and processes that makes it so, and it is the task of the criminologist to explain the connection by identifying the mechanisms producing this effect. A mechanism can thus be defined as the modus operandi that makes a situation transform or not transform into something else. More specifically, I propose that "mechanism" is defined as a cause of a (causal) conjunction, a cause that has a (causal) relationship as its effect. 
As Louis Althusser said: to positivism, reality is smooth and homogeneous, while it is actually deep and complex. Positivism views reality as a surface consisting of phenomena that can be identified and observed in a systematic, relatively unproblematic manner. This monistic ontology has been questioned many times during the history of philosophy. Not least the development of science has frequently resulted in the formulation of alternative ontologies.

Although sociology differs from natural science in many respects, of course sociology should nevertheless carefully study the methods and theory-constructions of natural science in order to find inspiration and models for its own activities. In the following I will deploy a description of the historical development of the natural sciences and then, by way of analogy, transfer the idea to sociology.

In previous centuries the object of study for the natural scientist was-Nature. $\mathrm{He}$ - it was a he - mastered most aspects of nature's mysteries, from chemical reactions and the life of insects to the dynamics of the universe. Gradually specialization and the division into disciplines replaced this encyclopedic competence. Today, nature is divided into a large amount of subject areas and subareas, corresponding to an equally large amount of academic specialties and sub-specialties. This division is not arbitrary - it is not merely an effect of academic competition and political decision. Indeed, there seems to be a historical and logical, or rather ontological, order for the divisions.

The order indicates that nature is divided into levels. First come mathematics, then physics, chemistry and biology. These broad categories can be divided into subcategories, providing us with an evolutionist stratification of nature in a subatomic level, an atomic level, a molecular level, a cellular level, an organic level, and so forth upwards. The logic is, first, that each lower level is a precondition for the existence of the higher levels; no flowers without cells, no cells without molecules, and no molecules without atoms. Second, lower levels can offer a partial explanation of higher levels. Third, the higher level has a certain, relative autonomy in relation to the lower-laws and empirical phenomena at the higher level cannot be completely explained by reduction to the lower. Each level has an existence sui generis. Fourth, higher levels constitute surroundings or environments that may have causal impact on phenomena at lower levels.

This view of the object of natural science can be called a level ontology (Bunge 1973, Johansson 1989), or an irreductive ontology. It focuses upon the actual praxis of modern science, which is an extreme division of labor on the basis of different types of structures, causal mechanisms, and observations. Thereby it differs drastically from the numerous attempts to reduce reality to one ultimate level characterizing the mechanic reductionists of the early $19^{\text {th }}$ century, recurring in logical positivism's notion of a unitary scientific language. The reductionists tried to find the basic formula, the law by which all aspects of reality could be accounted for, the ultimate level of all levels. 
The point of this reminder is that I want to claim that modern sociology is situated in a position paralleling the phase of natural science of the early $19^{\text {th }}$ century, i.e. in the rupture between encyclopedic knowledge and reduction. At present, in most social sciences there is a widely held conviction that social reality can be reduced to one level, to one formula. Let me cite a few examples of this. Karl Popper (1969: 98) expresses his version of the so-called methodological individualism in the following well-known manner:

All social phenomena, and especially the functioning of all social institutions, should always be understood as resulting from the decisions, actions, attitudes etc., of human individuals, and that we should never be satisfied by an explanation in terms of so-called "collectives".

All that is social must be explained at the individual level. A contrary position is found in e.g. Michel Foucault's (1968: 203) structuralism:

It is not man himself who thinks but he is thought by the thought system he happens to be caught in, he does not speak but is spoken by the language he is born into, he does not act but is acted by the social, economic, political systems he belongs to. These changing structures perform as his master and destiny.

The young Foucault puts parenthesis around the individual subject; the structure explains everything.

These two positions are examples of downward and upward reduction. They may be seen as extreme poles in a continuum between micro- and macrosociology, and they remain very common today. If collectivist and holist perspectives were predominant during the 70 s, the 80 s up to our days have been dominated by methodological individualism. Perhaps the best example of the latter position is Gary Becker, James Coleman and the theory of rational choice.

A similar issue is the so-called agent-structure problematic. The most frequent attempt to resolve this problem involves suggesting a middle-position or synthesis. One of the more familiar examples is Anthony Giddens' theory of structuration, which by the formula "Structures are both the medium and the result of social action" claims to strike a balance between actor and structure by including both sides of the dichotomy. The same goes for Bourdieu's concept of habitus, which merely rephrases an analytical problem. As I have shown in another context, formulas of these kinds resolve nothing but rather conceal the problem by labeling it, drawing a tarpaulin over it. In place of analysis of a complicated problem we are offered a blindfold (Brante 1989).

\section{GAUSAL REALISM AND SOGIOLOGY}

Having outlined a meta-theoretical background, let me now turn to a strategy for improving sociological theory. Just like the reductionists of the $19^{\text {th }}$ century, many current meta-sociologists seek to find the basic and all-encompassing formula 
by which all social phenomena can be explained. In my opinion these attempts to reduction or synthesis of everything remain unfruitful, probably impossible. They tie the sociologist since he or she becomes a juggler with too many balls in the air, too much that has to be fitted into the formula. I would suggest that we, analogous to natural science, attempt a level division of the general object of knowledge of sociology. Just like natural scientists have successfully carved up the "seamless web" of nature into fruitful areas of study, social scientists should try to increase and sharpen their focus by cutting up the "seamless web" of society according to its building blocks.

The alternative strategy I propose combines the concepts of causality, mechanisms, and society as stratified reality. First, if we take the actual research performed by sociologists seriously and inductively separate the levels that seem to be presupposed in current sociological research, we reach the conclusion that sociology actually does produce knowledge on several levels. So the question becomes how many levels should be identified. ${ }^{11}$ Possibly, future research will identify seven, fourteen or why not thirty-six different social levels. Adhering to Occhams principle, in this context I will merely illustrate the idea by distinguishing five levels in contemporary sociology. Second, we have to formulate a general purpose of theoretical sociology, regardless of level. In accordance with the foregoing, I propose that the ultimate goal of sociology is to identify social structures harboring causal mechanisms that generate empirically observable effects. Combining these two steps, we arrive at the conclusion that each level below contains specific, relatively autonomous structures, and that the goal of sociological theory is to map out the respective mechanisms for each structure in order to be able to explain social phenomena.

This definition of the purpose of sociology corresponds reasonably well with Roy Bhaskar's definition of the object and task of sociology. According to Bhaskar (1989: 71, 72) the object of sociology is social relations, and the task is to explain the reproduction and transformation of social relations. (I agree with Bhaskar with the proviso that it is a too strong constraint to study only relations between entities. The content of the entities - the components constituting the structure - are of relevance and should be included in the research object. In the sketch below I commence from Bhaskar's notion but hold that the content of the constituent components is accounted for by the nature of the specific level.) Thus each level below involves relations between certain types of level-specific components.

\section{SOGIOLOGY DIVIDED INTO LEVELS}

International level. Treats relations between components such as nations, transnational companies and organizations, often viewed in a global perspective. This level have been elaborated by peace- and conflict research, world systems analysis, center-periphery theory, dependency theory, theories of imperialism and 
colonialization, globalization theory. Examples of influential sociologists are Shmuel Eisenstadt, Immanuel Wallerstein, Theda Skocpol, Charles Tilly, Manuel Castells.

Inter-institutional level. (In practice often national level). Treats relations between components such as institutions and organizations, often by employing theories of historical and social development in general. The purpose is to describe and on a broad level distinguish institutional orders from the perspective of the societal order; for instance between economic, political and ideological structures as they are analyzed by the concepts of mode of production and social formation, or between state, market and civil society, or by the functions of institutions such as in Talcott Parson's AGIL-scheme, or Mary Douglas' gridgroup model of links between institutional order and cosmology. Examples are most classics and, for instance, the works of Norbert Elias, Jurgen Habermas and Niklas Luhmann.

Institutional level. Relations between components such as formal and informal status positions, social roles, position in networks, in everything from companies and public hierarchies to groups and families. Weber's theory of bureaucracy was followed by a research tradition called organization sociology that seeks to account for internal and external relations and modes of function of organizations, such as contingency theory, technology theory, "garbage can" theory. Neo-institutionalism is another example. Some modern leading figures are Pierre Bourdieu, Robert Merton, Joan Woodward, Charles Perrow, James March \& Johan Olsen, Mark Granovetter.

Inter-individual level. Relations between individuals in direct or face-to-face interaction. This level has primarily been elaborated by symbolic interactionism. However, the person that first and foremost has "discovered" this level and formulated theories of its mechanisms is Ervin Goffman. According to Goffman, interaction creates an order sui generis, following its own laws and structures. Interactions are rituals producing something Goffman calls unio mystico, living their own specific lives. In various shapes this thesis has been elaborated by e.g. etnomethodology, having as its object of research conditions and rules necessary for everyday human interaction. Sociological conversation analysis is another follower. Goffman's research program has been developed by e.g. Randall Collins, Anne Rawls, Jonathan Turner.

Individual level. Relations between intra-individual components, and how such structures form the ground for individual autonomy and self-creating activities. The standard example is theories of the social self, e.g. Mead's theory of the relationships between the I, the me, and the generalized other. Festinger's theory of cognitive dissonance is another example. To this level should also be counted postmodernism's theories of identify formation as well as notions of human 
nature and the modern individual basic to socio-biology and rational choice theory. Recent well-known elaborations of the individual level have been conducted by e.g. Margaret Archer, Jon Elster, Norbert Wiley, Hans Joas.

Of course, this division can be expanded whereby we approach other subjects, upwards towards anthropology, downwards towards psychology and biology. In addition, since the division into levels is derived from a consideration of the main areas around which sociologists form clusters, it should be emphasized that it is not merely inductive but also historically contingent. For instance, in view of contemporary development towards "globalization", manifested in world economic networks, increased cultural interchange, and new international law systems like the European Union, it is conceivable that the importance of and interest in the national level will decrease, giving way to the global level.

Moreover it is possible to supplement the vertical axis of levels with a horizontal axis by using the concepts of social structure and culture, system-structureagent, or structure-discourse-actor at each level, whereby we obtain a 10- or 15 field table signifying that sociology has an objective and a subjective side, and also an acting side. ${ }^{12}$ Since "culture" and "actor" are also structured entities, and since the social, the cultural and the actor are "mutually sustaining" (see e.g. Sewell 1992), I preserve the term "structure" to the combination of these factors. It would look something like this:

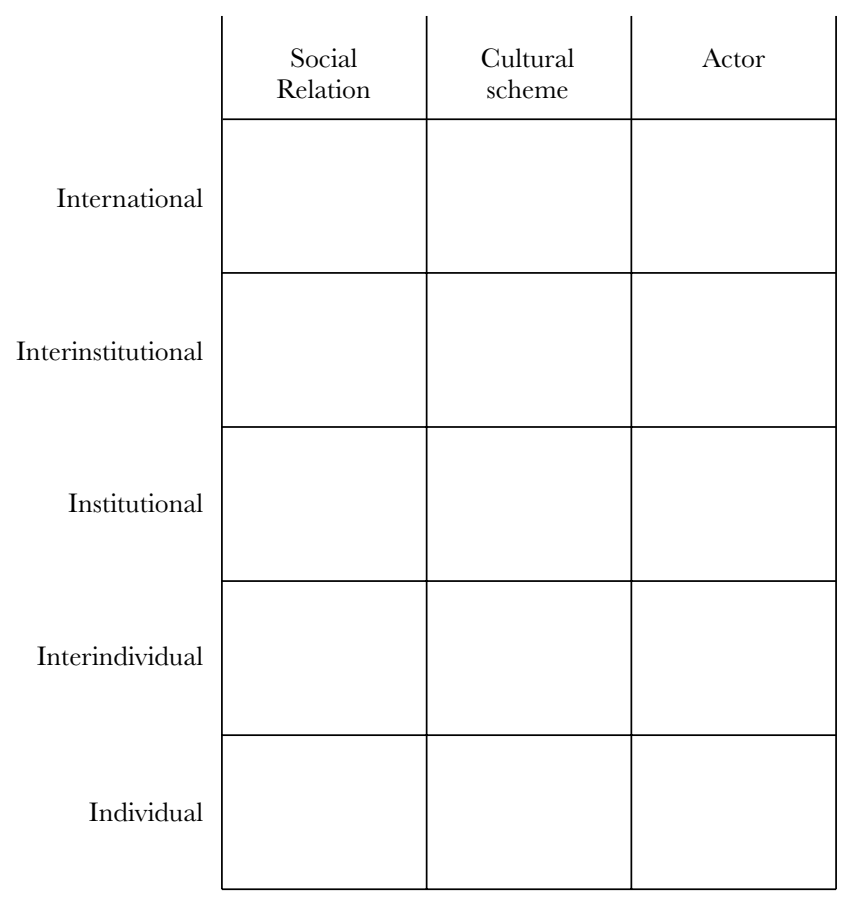


The research hypothesis forming the basis for the above division is the conjecture that each level has an existence sui generis. One first piece of evidence for this conjecture is simply that contemporary sociology is focused around and concentrated upon disparate levels, indicating that they are indeed regarded and treated as involving relatively autonomous, non-reducible objects. Level-autonomy thus resides in non-reductive causal mechanisms of particular sociological interest at each specific level. (So if we do not think that thousands of sociologists are totally "off the track", as it were, we can at least surmise that the conjecture is not completely unfounded.)

1. Ordinarily, level-sociologists identify three levels, called micro, meso and macro. My partition into five levels builds on the following simple reasoning. An individual does not exist in a vacuum but is to a great extent a product of the social (the cultural included). Attitudes, intentions, dispositions, habitus, and so forth - the social properties of the individual - are inscribed via socialization. This social self is a product but also the raw material, one point of departure for explaining social action, which is why it constitutes a research area in its own right. This is also the reason why so much sociological research has attempted to separate the social self from "natural" components of the human being. Studies of the individual as a set of intra-individual elements, with a special focus upon inherent crucial causal mechanisms between social and other components, comprise what I call the individual level.

"The social" is internalized by interaction with other social creatures such as parents and peers. Interaction between individuals is another area that has been widely studied by sociologists, partly because interaction per se seems to constitute a particular type of norm- and rule-bound, often ritualized, behavior, thus governed by level-specific mechanisms. Therefore an inter-individual level is distinguished.

The properties of an individual is often generated and defined by her relations. Individuals cannot be parents without children, husbands without wives, employees without employers, nor Prime ministers without subjects. These relations or roles are prior to the single individuals that occupy them for a time and remain after their disappearance. The fact that the relations exist before and after the single individual implies that they have a special, non-reducible ontological status; that they define and influence the properties of individuals implies that they have causal power. ${ }^{13}$

Consequently, the relations inherent in institutions such as the family or the bureaucracy are relatively enduring structures. It is completely conceivable to study them per se, without invoking the concrete individuals that happen to occupy them. Thus it is possible to abstract from single individuals and their direct interactions and study the specific patterns that characterize an institution such as the family. At this level, we can study the typical causal relations 
distinguishing family structures, for example relations of authority and patriarchy. This is what I call the institutional level.

The typical family relation constitutes what we often call a social institution. This institution is embedded in other institutionalized relations - work, school, media, and law systems such as family law. Hence the family institution is one of many institutions, and we can abstract or go up one more level and study the relations between the family institution and other institutions without invoking the specific roles that comprise the family, that is, we study relations between institutionalized relations. This is the inter-institutional or national level.

This level is the classic as regards delineations of "the social". In most traditions the nation-state has been viewed as the basic unit of sociological analysis, characterized by a definite territory, cultural and political identity, economic selfsufficiency, a unified law system, and self-reproduction, comprising an autonomous system. Today, world development indicates that there is another emerging level that should be conceptualized as autonomous - the international or global level. Many recent studies seek to formulate a new, "global paradigm" (will probably be paradigms), the object of knowledge of which involves autonomous international structures, cultures and actors. Despite some efforts by the multi-culturalist school, the role of the family in a global world order remains to be explored.

The foregoing is nothing but a codification of what sociologists actually do. The levels can be studied and are studied as relatively autonomous because they comprise structures that involve specific mechanisms with causal capacity. These objects of knowledge cannot, however, be reduced to e.g. aggregates of individual properties. $^{14}$

2. Employing a level division of this or similar kinds together with a recognition that the levels contain specific properties, a great part of contemporary meta-theoretical debates about the relation between micro and macro, as well as various reductions, could be resolved, dissolved, or at least postponed. If Jonathan Turner (1988) is correct in claiming that the micro-macro problem cannot be solved simply because we know too little about micro and macro, studies centered upon identifying the causal mechanisms characterizing each level should take us further towards plausible answers to these riddles.

3. Older as well as modern sociological classics have often been interpreted as seeking to apply consistent and all-encompassing perspectives comprising both micro and macro. From such stances, Marx has been criticized for not having developed a social psychology and Mead for not considering the context, the "back-drop", in which interactions are carried out, and therefore, articles like George Homans' "Bringing Men Back In" have been written and read as critiques of parsonianism. Parsons is accused of not understanding that his actors are "persons of flesh and blood." Presumably, however, Parsons understood this, but his object of study was not at that level but at the level of role theory, i.e. the institutional level. From the point of view of causal realism, Homans' article is best understood not as a critique of Parsons but rather as a claim that at that 
time, other levels were underdeveloped. To express it more drastically: in the object of knowledge of the institutional level individuals do not appear as single personalities but merely as bearers of positions, or performers of roles. This means that what constitutes the "actor" in the figure above varies with level. For example, in theories about institutions, actors denote institutionalized actions such as specific role performances while theories exploring international structures and developments deploy nations, multi-national companies, armies and the like as main actors.

4. A division into levels facilitates systematic comparison of the explanatory potential of different traditions on each level, and conversely it will be meaningless to discuss the merits of sociological traditions by focusing on different levels. For instance, it will be futile to discuss whether functionalism or symbolic interactionism constitutes the "right" sociological perspective. To put it simply, they have their strength on different levels. Likewise contemporary controversies about power theories, theories of patriarchy etc. would be considerably tidied up if it were observed that power and sexual oppression are phenomena that are enacted at global, national, institutional, and interpersonal as well as individual levels. Consequently, they are effects of several causal powers; they are causally overdetermined. Disputes about whether power should be defined as e.g. latent resource assets or as the capacity of an individual to make another person act against his will would also appear meaningless, given a reasonable division into levels. Generally speaking the social phenomena sociology studies, e.g. stratification, class, discourse, power, gender, professions, welfare, illness, labor and so forth are events that are enacted and can be analyzed at all levels but usually with different conceptual and methodical instruments.

5. The last points imply that sociological theory never refers directly to reality as it immediately appears but to objects of knowledge, theoretical elaborations. This is quite obvious in the natural sciences, where idealized objects are used as points of reference (such as movement without friction, movement in vacuum, absolute zero temperature, and the like), i.e. the "object" does not exist in reality. Bourdieu (1991: 13) expresses the importance of being aware of this difference in the following typically drastic manner: "For the sociologist, familiarity with his social universe is the epistemological obstacle par excellence." In the next step, successful theories can be applied to explain (its parts of) reality.

To sum up. Each level constitutes a system or structure sui generis. In a different vocabulary, each level is a network of relations between nodes. The levels are distinguished by the characteristics of the nodes and the (causal) relations between these. At the interindividual level, the nodes are individuals and the relations may be domination and subordination, authority, contract, friendship, feelings of love, hate, or loyalty, bonds like marriage or parenthood, various kinds of behavior. At the international level, the nodes include nation-states, multinational corporations and organizations, and relations may include export and import, migration, aid, war, and so on. (Knoke and Guilarte 1994: 79). 
In the framework sketched above, mechanisms can be classified into two types. On the one hand we have those mechanisms providing autonomy to the levels, on the other mechanisms linking the levels. It would carry too far to discuss the latter here but let me just mention the classic concept of socialization, which is an umbrella concept for a number of powerful mechanisms linking individuals to the other levels, thus contributing to maintaining social order and integration. (Indeed, there is even an entire subject devoted to these links, called social psychology.) Let me now abstract one step and suggest a way of understanding the relation between levels in general terms.

We call the level we are interested in $(\mathrm{I})$, underlying levels $(\mathrm{U})$ and overlying levels $(\mathrm{O})$. Referring to natural science, Arthur Stinchcombe claims that causal mechanisms at level (I) are identified by analyzing the components of the level, which are at level $(\mathrm{U})$. Certain forms of market interaction, perhaps in particular behavior at the stock market (since it is closest to "the ideal market") can be accounted for by employing the theory of rational choice. Other interactions, for instance behavior on the marriage market, may need other assumptions about what mechanisms govern the components of the structure. An interesting point made by Stinchcombe is that assumptions made about elements at level $(\mathbf{U})$, that is the components for the structure of interest, do not have to be fully in agreement with specialized research at this level. He makes an analogy to natural science. Established theories like Boyle's law do not agree with modern theories of molecular movement. Yet the law is applied since the deviations at the lower level $(\mathbf{U})$ are too small to have any relevance at level $(\mathbf{I})$. In a similar vein, Stinchcombe argues, any good master's-degree student in psychology has no trouble demonstrating that economists' and sociologists' assumptions about individual rationality are erroneous, but at the same time "the assumption of rationality puts an economist in a position to 'explain' some features of market behavior" (Stinchcombe 1991: 368). Over-simplified mechanisms obtained from the lower level can within reasonable limits be useful for explaining processes at the level we are interested in.

I would like to supplement Stinchcombe by arguing that level $(\mathrm{O})$, which is situated over level (I), is also of great causal importance, providing the context to the phenomena we want to explain. From level $(\mathrm{O})$ we can, via sociological theory, get the dimensions that constitute frames for events at level (I), and from level (U) the dynamics of the process is obtained (Brante 1994).

Thus the relation between the levels can be summarized by three crucial concepts, one for each level: component $(\mathrm{U})$, structure $(\mathrm{I})$, and context $(\mathrm{O})$. The mistake of methodological individualism is to reduce levels $(\mathrm{I})$ and $(\mathrm{O})$ to level $(\mathrm{U})$ and the mistake of holism is to reduce $(\mathrm{I})$ and $(\mathrm{U})$ to $(\mathrm{O})$. Thus, a complete explanation of a social event would look like this: $e=f(U, I, O)$. 
To summarize. According to causal realism, the fundamental task of sociological theory development is to a) identify the mechanisms specific for each level, and b) identify the mechanisms that bind the levels together. While the former explain the autonomy of the levels, the latter explain how micro processes influence macro situations, and vice versa.

\section{AN EXAMPLE FROM THE INTERINDIVIDUAL LEVEL}

The next step in this elaboration of causal realism and level divisions would be to illustrate each level with examples from sociological theory. Lack of space prevents me from doing this in the present paper, so let me end this outline by offering an example concerning the level the autonomy of which is probably hardest to accept, the interpersonal level.

As mentioned, most social phenomena can be analyzed at each level. Phenomena like power, stratification, class, patriarchy, labor, market, professions, and so forth are manifested on all levels but assume different expressions at each level because they are structured in dissimilar, level-specific ways and must thus be analyzed with different methods. One example referred to above is the institution of the family. The family is a global phenomenon with a several thousand years long, changing history; it has been and remains the major institution for primary socialization; it is surrounded and regulated by laws and informal rules; it consists of a set of comparatively clearly defined roles and status positions; it is central in regards to interpersonal interaction and small group interaction; and it carries a considerable causal power for individual personality development.

The family as a system of interaction has been analyzed in sociology by concepts like role pairs, role triads, complementarity, alternatively as an institution of oppression, and so forth. Nowadays however, the interpersonal level of the family is primarily analyzed by psychologists and family therapists, as a clinical as well as a theoretical phenomenon. A simple illustration of a typical process used for analysis is the following:

The woman, who wants less intimacy, withdraws. The man, who wishes more intimacy, nags and criticizes. The more he nags, the more she withdraws. The more she withdraws, the more he nags.... From the outside, you perceive a constant circular interaction where attempts to resolve the problem entails that the problem is reinforced.' (Slightly changed quote from Helgesson 1996: 75)

Cases of this kind can be analyzed as feedback processes, as examples of reciprocal causality, or the like. My point here is that there exists an institutionalized context $(\mathrm{O})$ that may be called marriage or institutionalized pair relationship rendering the process possible. The institutional order provides the macro conditions for the very existence of the process. Further there are two components $(\mathbf{U})$, 
that is, two genus-socialized individuals supplying the dynamics or energy of the process. But the process in itself is understood at its own level (I), that is, it is the interaction per se, the reactions to the other's actions, that constitutes the structure that leads the pair into a vicious circle, a self-perpetuating system. And this is what Goffman means when he claims that the interpersonal level contains its own laws. A conversation can constitute a "unio mystico," locking the participants into a ritualized game. In this case the criterion of autonomy may be that each participant acts in ways that he/she would not do in another context, or alone. The very interaction and the shared access to "the facts of the situation" (including emotional moods, norms, rules and so forth) possess its own properties, imprisoning the participants. In other words, the structure cannot be completely understood by being reduced to either the family institution $(\mathrm{O})$, or to the individual characteristics of the participants $(\mathrm{U})$; it is the interaction as such $(\mathrm{I})$ that generates the effect. To use Anne Rawls (1987: 145) apt observation: "Goffman argues for the existence of social facts which are not the effects of routinization, not defined by social structure and not derived from individuals."

\section{SUMMARY AND CONCLUSION}

Sociology is an intellectual discipline and should indeed remain so. But the question is if we should let philosophical discourses about, say, the possibility of knowledge, capture us too much. There is a risk that we end up like Freud's patient who always polished his glasses but never put them on. That is why at the present time, simplicity in matters meta-theoretical is a good strategy. One reason for simplicity was stated by Chandler, another is that sociology is such a complex subject that its practitioners should not be too distracted from its main goals, and two domains requiring hard intellectual work may be one too many. So if a simple platform could be formulated and accepted, more time and energy could be devoted to the main objectives of the discipline.

This point can be put in another way. The approach suggested here implies that a sociological metatheory should not start with the epistemological question:"What can we know with certainty, given that our sense-impressions sometimes deceive us and that we are prisoners in our own linguistic categories, theories and expectations?" Instead I tried:- "Approximately what must reality consist of, given that we sociologists actually do produce knowledge about it?" While the first question takes us to the classical philosophical wheels of -isms and-logies, the second question generates more empirical studies and theory development. "First ontology, then epistemology" would therefore be a better order for contemporary metatheory.

In this paper a number of issues have been hastily touched upon why a summary of its main points may be in order. First, causal realism was contrasted to positivism and ultra-relativism. Of course, the latter approaches are both 
valuable; quantitative variable analysis as well as careful factual description, narratives, interpretative schemes, and grand classifications are necessary presuppositions in most sciences. However, my argument has been that the current trends tend to blur the ultimate goal of sociology, the production of causal explanations of social phenomena. Therefore they should be seen as useful auxiliary activities to be guided by a causally oriented sociology, not as end-goals in themselves. Further, because of their mysterious connotations and general vagueness, both positivism and ultra-relativism tend to necessitate years of cumbersome philosophical studies. Realism does not have these implications; on the contrary, its main tenets are not counter-intuitive but easily acceptable from a common sense point of view. (Indeed, I don't think the Sokal incident could have occurred, given a realist social-scientific platform. ${ }^{15}$ )

"Realism" was employed to signify ontological assumptions, especially that sociology has an object existing outside of sociological discourse. The advocated position implies realism in regards to social entities but not objectivism in regards to sociological theories and models. That is, "social facts" such as organizations, families, interactions, individuals and so forth exist, they are real, and they influence human behavior. Which theory or model of reality that is most true or provides the best explanation is, however, another matter. At the present time, since there is no absolute concept of truth but only incommensurable paradigms, theory-dependent facts and so forth, a meta-theory must remain agnostic to questions about theory choice, i.e. theoretical pluralism within limits as described above should be recommended. ${ }^{16}$

Realism also implies the epistemological position that we have at least partial access to social reality, enabling valid but fallible knowledge about it. Jane Azevedo (1997: 65) expresses the basic tenet of a realist epistemology with admirable simplicity: "the validity of our knowledge claims is, at least in part, determined by the way the world is."

"Causal" in causal realism was employed to suggest a general orientation in sociological research, viz. to explain by identifying generative mechanisms. It should be emphasized that the suggestion implies that concepts of mechanism, causality and explanation must be recaptured from the positivistic tradition. In particular, they must be tied to ontology, not merely epistemology (Nash 1999). For example, the conception of causality suggested here differs drastically from the positivist conception since it is not overly constricted by epistemological anxieties but is based on ontological concerns making it considerably more open, admitting non-observable causes, structural causality, causes that are never manifested in observable effects, causes that appear only once, perhaps functional causality, and so forth. ${ }^{17}$

In the second section I began with the ongoing debate between methodological individualism and holism, micro- and macrosociology. By way of an analogy to the natural sciences, I suggested that a way out of these dilemmas is simply to start with accepting what is happening in contemporary sociology, that is, extensive 
work is being undertaken on several levels, producing relevant knowledge and plausible explanations. If this is accepted, a level division more or less suggests itself. So to my mind, sociology of the new century would benefit from employing a level ontology and to seek to identify specific objects of knowledge for each level. This would mean that new, theoretically informed research tasks would be developed for sociology at each level. A level division would enable the sociologist to focus more exclusively on the puzzles of his or her favorite level; it would facilitate comparability between rival explanatory models at the same level; it would foster cumulativity; and it would lead to a deepening of specific theories. It is possibly in this way, by having a common basis in an uncomplicated metatheory that is fitted to the needs of the subject, providing it with a clearer, stabilizing orientation, that sociology could change from its present fragmented and defensive position to assume a more socially relevant and offensive role. If sociology shall avoid loosing its autonomy, turning into social statistics and/or ethnology and/or quasi-philosophy, it is vital that it raises its ambitions. Since "there is nothing as practical as a good theory", theoretical advances would most likely facilitate a transformation of sociology into a more strategic, interventionist science. Be this as it may, a level-ontology coupled with a causal approach probably constitutes one of several possible first steps towards the epistemological break that is necessary if sociology wants to leave its present phase of Naturphilosophie and become a genuinely explanatory science.

\section{Thomas Brante}

Department of Sociology

Box 114

University of Lund

22100 Lund

Sweden

E-mail: thomas.brante@soc.lu.se

\section{NOTES}

${ }^{1}$ In my opinion however, it is erroneous to say that sociology finds itself in a special, acute crisis today. The situation was approximately the same ten, twenty, and thirty years ago. Of course, this all depends on how we define the concept of crisis. Employing Thomas Kuhn's definition, not merely sociology but large parts of social science have been in a crisis for more than 30 years now. As we all know, Kuhn defined crisis as departure from normal science. During a crisis, practitioners begin examining the basic assumptions of their discipline, its philosophical assumptions and methodological principles, and start looking for paradigm candidates. The crisis ends when the main presuppositions of the discipline are again taken for granted. Now I do not think that sociology ever has been or will become a normal science in this sense. Clearly, however, the end of the 1960s was characterized by philosophical deep-sea diving followed by the emergence of a 
plethora of sociologies under the label "let a hundred flowers bloom" — a ramification of paradigm candidates we have still not recovered from.

${ }^{2}$ Our identity can no longer reside in a common methodology. Our methods and techniques of data collection - interviews and surveys, public statistics, statistical elaboration and so forth - are shared with most social scientific disciplines. Neither is it a particular subject matter or area that provides identity - our objects of study, such as formal organizations (political science), interaction (psychology), cultural artifacts, experiences and mores (ethnology), oppression and poverty (social work research) - are inhabited by others. Our identity resides in, and must reside in, our particular perspectives and conceptual frameworks and our own models of explanation, that is, in our theories.

${ }^{3}$ As we all know by now, reality is not observed directly but in mediated form, hence the concept "object of knowledge", also called "transitive object", "problematics", and more. Presumably, the simplest concept is "model", although it may give mistaken associations since "model" is also employed for more contingent constructions of conceptual systems. "Object of knowledge" refers to basic and shared images of a subject matter constituting the platform for a generation or school of researchers. Thus it refers to something that is already theoretically elaborated, not "spontaneously observed" reality. The object of knowledge is a presupposition for explanation, or in Foucault's terms, it: "allows one to define the precise domain in which a causal relation will be able to be located." (Quoted from Davidson 1997: 13).

${ }^{4}$ Especially Paul Feyerabend has been read as pursuing a strongly relativistic program, and to be responsible for justifying subsequent ultra-relativistic philosophies of (social) science. However, as can be seen from his small remarks here and there in Against Method of 1975, Feyerabend himself never believed in extreme relativism, an issue he takes care to expand in his last, 1993 volume of this book. Basically he drives home two points. First, arguing against the belief in the existence of The Scientific Method, he concocted its antidote. For instance, the slogan "anything goes" was not meant to be taken literary but was to be seen as a medicine against too much rationalism, a balance to the overly naive faith in Western science. Thus he followed Kierkegaard's motto that if you want to correct an imbalance, exaggerate as much as you can in the other direction. Second, he showed that "anything goes" must follow if you are a serious and honest rationalist studying the history of science, which Feyerabend was not. Throughout, he called himself a realist.

${ }^{5}$ On the one hand, of course all sociologists are constructivists, and society at large is a construction. That is, if it is claimed that society or social phenomena are constructed in the sense of being manmade, or that human beings and human actions are required for the existence of society, this is trivially true and everybody agrees. If it is claimed that scientific facts are constructed by humans beings in the sense that a language (manmade) is needed in order to express scientific facts, or that our theories influence what we consider to be facts, I couldn't agree more. On the other hand, if it is claimed that scientific facts are nothing but constructions, that they can be reduced to texts, instruments or the like, or that they are constructions and thus can't be trusted because they are always biased, I do not agree. The content of scientific facts is a product of many factors. One of these is reality. Indeed, it could be argued that the specificity of science is precisely that its various methods and instruments are intended to open windows to reality in systematic ways. The set of scientific methods, together with the norm system of the scientific community, is designed to capture and reveal the essence of reality (See also Azevedo 1997 on this point).

If it is claimed that there are no philosophically absolute scientific criteria I agree: scientific criteria are socially and historically changing values. If this is interpreted as implying that there are no means of separating true and false knowledge, or even that all kinds of knowledge are equally good or bad, that is, a total relativism, I don't agree. As 
Rorty (1982: 166) dryly points out: “'Relativism' is the view that every belief on a certain topic, or perhaps about any topic, is as good as every other. No one holds this view."

In my opinion, the most interesting idea of constructivism, turning it into a fruitful sociological hypothesis, is that certain social phenomena and processes are created by preconceptions. The most well-known example is Merton's self-fulfilling prophetia: If people believe that a bank will crash they run to the bank and withdraw their money, whereby the bank crashes. If people believe you must be out early to get tickets to a popular movie, you must be out early to get tickets to this movie, and so on. Schelling (1998) has discussed and exemplified this type of mechanism. A similar mechanism is described by Ian Hacking (1986: 228), holding that: "In some cases, our classifications and our classes conspire to emerge hand in hand, each egging the other on." The constitution of parts of reality, such as the mentally ill and other groups, is generated by the help of the categories we use in order to define, delineate and treat them. Already in 1911, W.I. Thomas formulated the constructivist agenda in his famous statement: "If men define situations as real, they are real in their consequences." However, since it holds only for some cases, this proposition should not be considered a general law but as an empirical research hypothesis.

${ }_{6}^{6}$ There are of course exceptions to this sweeping account. For instance, there are social constructivists who do not wish to call themselves relativists. The question is, however, if you can be a constructivist in the strong sense without being an epistemological relativist. I would say not, but in the end it all boils down to a matter of definition. (And where do we find a clear definition of constructivism?) For the difference between strong and weak forms of constructivism, see e.g. Sayer (2000).

${ }^{7}$ I regard critical realism as the most promising philosophy for social science of today, and for the purposes of the present article, I might as well have used this concept. The problem of critical realism does not reside in its basic content but in its terminology and some of its claims. The term "critical" serves to relate a science to an emancipatory ideal. However, neither Bhaskar nor any other critical realist has succeeded in establishing a link between critical realism or science and a political program, be it socialism or emancipation. The basic reason is, to put it simply, that it is not possible to establish such a connection except in the general sense that correct knowledge of conditions and causal relations is a useful instrument for attaining desired goals. And this insight is not specific to realism, or to any particular political program. That is, not even critical realism succeeds in transcending the divide between facts and values. Secondly, I regard the term "causal" a better prefix to realism since it is the ontological recognition of underlying, unobservable, generative causal mechanisms that constitutes one of the most basic distinguishing marks between realism and most other philosophies of science.

8 "Stratified reality" is also often used for signifying differences between the realms of experiences, events and mechanisms. There are a number of other crucial realist concepts the implications of which for sociology needs to be carefully worked out, such as open and closed systems, intrinsic and extrinsic relations, emergence, generative mechanism, see e.g. Collier (1994) for an account.

${ }^{9}$ I will not delve into the relation between understanding and explanation here, but agree with Bourdieu (1996) that "Against the old Diltheyian distinction, it must be accepted that understanding and explaining are one," or rather, that understanding is the psychological side of (theoretical) explanation.

${ }^{10}$ The differences between realism and positivism or relativism comes out clearly in the definitions of crucial concepts in the philosophy of science. As is well known, David Hume defined cause as a "mental habit." This conclusion is reached if one sets out solely from certain epistemological assumptions about what is possible to know about the world. Today, we have a similar situation as concerns the concept of mechanism. Let me illustrate. 
Words have different ontological references. Words like e.g. theory, hypothesis, acount, explanation, signify theoretical entities (or entities belonging to world 3 in Popper's ontology). Other words, like stone, horse, magnetism, power, social structure, signify entities which exist or are assumed to exist in the external world. To my (realist) mind, mechanism (and cause) are words of the latter kind, signifying entities existing in the external world (world 1, to Popper).

Now, in a recent book on social mechanisms (Hedström and Swedberg 1998), several authors define "mechanism" in a completely different manner. Raymond Boudon (1998: 172) defines a social mechanism as a "well-articulated set of causes" (my emphasis); Thomas Schelling (1998: 32) defines it as "a plausible hypothesis, or a set of hypotheses", alternatively as "an interpretation"; Diego Gambetta (1998: 102) sees them as "hypothetical causal models"; Stinchcombe (1998: 267) defines them as "bits of sometimes true theory", or "model"; and Hedström/Swedberg (1998: 13) call them "analytical constructs." Obviously, mechanisms belong to world 2 or maybe 3 in Popper's sense, the word refers to theoretical entities. At the same time, the aim of this antology as well as to social theory in general is to "systematically explicate the social mechanisms that generate and explain observed associations between events" (1). Now if we, perhaps a bit impolitely, combine these two types of statements from the same book we arrive at the conclusion that the aim of sociology is to identify bits of theory. However, bits of theory, accounts or models can hardly be something that generate observable associations between events. Positivism and idealism often run into self-inflicted problems; maybe they should rework their epistemology and take a closer look at common sense ontology. Approximately the same point about the relation between words, the signifier and the referent recurs in a debate about discourse theory between Bhaskar (realist) and Laclau (idealist), see Laclau and Bhaskar (1998: 14).

${ }^{11}$ Of course, level divisions are familiar in social science. Durkheim separated society from the individual, Parsons distinguished between personality, society and culture, Habermas uses life-world and system, Giddens agency and structure, and George Ritzer identifies ten levels, to just name a few. One problem with some level divisions is that they are not systematic, that is they do not set out from one dimension but rather conflates substantive areas with analytic levels. Ritzer, for instance, separates "organization" as one level, "family" as another. However, "family" is a substantive area of research that must be seen as one form of organization.

12 Social relation refers to the classic object of study of sociology; comparatively enduring patterns between social "components", for example divisions of labor (differentiation) or relations of dominance and subordination; power, status, prestige (stratification). Cultural scheme signifies what have been called ideology, Weltanschauung, cosmology, perspective: meaning-carrying and meaning-providing symbolic networks. While patterned social relations has been the object of e.g. the Durkheimian, Marxian and Parsonian traditions, the Weberian tradition, symbolic interactionism, ethnomethodology, and more recently, cultural studies, have had social meaning as their main concern. Ordinarily, both strands have defined their fields of study as relatively autonomous phenomena. Conversely, the relationship between the social and the cultural has been the traditional focus of study for the sociology of knowledge. Finally, actor or agent refers to socially positioned and culturally permeated dynamic components of each level (individuals, organizations, nationstates). In the vocabulary of systems theory, the mutual dependence between these three entities at each level constitutes the foundation for a conceptual framework for studying each level as a relatively autonomous, structured system.

${ }^{13}$ In contemporary sociology, to claim that the levels are autonomous is one thing, to say that they are real is another. To my mind, however, nothing can be called autonomous if it is not in some sense real. So are the levels real? 
First, it should be pointed out that the easy way out of this query is to say, like Parsons, that levels are merely "analytic devises." That answer silences most people. However, it is a bit too easy, leaving some questions unanswered (such as: How can an analytic device explain anything?) and I will not take that route. That the question is still a problem is shown not the least in a recent book by Neil Smelser (1997), displaying a clear ambivalence. On the one hand, Smelser holds that "without taking into account the constraints of higher levels of social organization is to fail as sociologists" (p. 47) and that "it is impossible to understand and explain events, situations, and processes of 'lower' units without appealing to some higher order of organization by which they are constrained" (p. 31). I agree. However, in the same paragraph he says that "This acknowledgement does not call for any special assertions about reality, but rests on the need for higher-level organizing constructs necessary for comprehensive explanations", and on p. 29: "Other levels of reality are analytically as important as - more important for some purposes - the person." (my emphasis) So for Smelser, macro-structures seem to be both analytic devices and real-a clear contradiction in most senses of these terms. After having touched upon the problem, just like Parsons he chooses to take the easy way out by "exiting": "I do not wish to enter into all the ranges of controversies and misunderstandings that have surrounded these issues over time." (p. 47).

So let me try to answer this question, not by going back to the old debate between methodological or ontological individualism and-holism, but again by using a simple analogy. Let us imagine a set of pictures and maps - if this was a lecture, I would have used transparencies - and let them correspond to my five levels of sociology. First, we imagine a picture correspondent with the individual level, a photography of a typical Lisbonian sitting next to the statue of Fernando Pessoa at the outdoor café A Brasiliera in the center of this town. Picture number two shows two Lisboans happening to meet among the crowds at Largo Rossio and stop to chat, whereby a "face-to-face encounter, an interaction ritual" is carried out. Picture three is a map of the city of Lisbon showing its institutionalized organization; patterns of streets, buildings, parks, bridges and rivers; the spatial structure of the city is clearly visible. Picture four is a map of Portugal in which Lisbon is marked out and connected to the rest of the country by roads and railroads. Picture five is a world map in which Portugal and Lisbon are clearly connected to the rest of the world by flight routes, boats, satellites and other means of communication enabling the internet, TV, cellular phones. Now the somewhat silly question is: which of these pictures is most true or real? Which one gives the most useful account of Lisbon? The answer is of course that all are true, all represent reality, and that which one is most useful depends on specific purpose and interest. No picture can be "reduced" to another; all contain information and can be used to carry out practical things and to explain events and non-events in Lisbon.

Now, I would argue that the sociological levels I have suggested possess a similar kind of existence. For instance: in a city like Lisbon you are more or less forced to follow the structures of the city; you cannot go through buildings, and if you try to cross Avenidas da Liberdades at five o'clock in the afternoon you will get killed or end up in hospital. Thus there are a number of spatial and material rules that must be followed, or rather, physical objects causing you to move in Lisbonian time-space in certain determinate ways. Similar conditions prevail in social timespace, you are caused by, nay, physically forced to follow the institutional norms and regularities ("routines", "mores") of the social. Attempt bigamy and you are put in jail since there is an institution called the family that is backed up by repressive law. Behave oddly, i.e. deviant, and you end up in a mental hospital. In fact, I think this is the main thrust of Durkheim's advice: treat social facts as if they were things.

So in this sense macro structures are real. They have strong effects that are utterly noticeable, esp. when violated. Just like in a city, you normally follow the social streets, 
walk around buildings/institutions or enter them, avoid the police/being excluded - life is governed by external, constraining and enabling structures, be they physical or social. Individual movement cannot be understood without taking the physical structure of the city into account. In a similar vein, individual behavior cannot be understood without taking social structures into account. That is why macro-structures are real and autonomous. See John Searle (1995) for a different way of arguing for the reality of "institutional facts."

${ }_{14}$ The phrase "aggregate of individuals" immediately brings to mind the rather worn-out discussion between methodological individualism and holism, going back to the ancient debate about nominalism vs. conceptual realism. The most common holist defense for its case is of course the argument that wholes are something more than their parts, for instance that a melody cannot be reduced to its individual tones, a molecule cannot be reduced to aggregates of individual atoms, a lion's behavior cannot be explained by its cells. ... I will not go into this debate but just want to state that to my mind, the strongest argument of this debate is the fact that methodological individualists do not follow their own dogma, that is, they do not reduce other levels to the individual level but go further. Individuus means indivisible, but individualists always decompose this entity. To postmodernism, the individual is decentered into a set of fragmented identities, to sociobiology to DNA-maps, to many AI-researches she is a hairy computer, to rational choice theorists the individual is reduced to preferences plus knowledge plus logic. All of these reductions deploy unobservable intra-individual entities and thus the ontological argument that "after all, it is only humans that act, can be observed, etc," is just rhetoric.

${ }^{15}$ In 1996, physicist Alan Sokal published a paper in Social Text suggesting a link between quantum mechanics and post-modernism. The same day it was published, he announced that the article was a hoax. My point is that the extreme vagueness of the conceptual apparatus of post-modernism and cultural studies made the incident possible. See e.g. http://www.drizzle.com/ jwalsh/sokal/

${ }^{16}$ Scientific criteria are historically and socially changing values. However, the absence of an absolute Archimedean point does not imply that scientific criteria are useless or that all knowledge can be put on a par. Rather, it means that criteria should be seen as Lakatosian research programmes; criteria can be useful for a while, for a particular subject.

${ }^{17}$ Granted such a concept of causality, a well-known difference between physical and social science can be formulated in a new manner. Physical science explains material structures and processes by means of discipline-specific conceptual apparatuses. During the course of history new concepts emerge while others are discarded. A primary reason for the rejection of some concepts is that they are shown not to denote real causal processes. For instance, the concept of phlogiston was rejected from chemistry at the end of the $18^{\text {th }}$ century. It explained nothing since it did not denote a material phenomenon. In social science, by contrast, concepts with no material reference may have very strong explanatory force since beliefs and experiences can be strong causal powers. For instance, a concept like "God" denotes a belief about something that does not exist. Simultaneously the belief as such is a social fact that has generated immense historical and social effects. In other words, both material and mental causal mechanisms belong to the object of social science, and material as well as mental explanations are not merely permitted but indeed indispensable.

This is the perspective from which sociological trends like social constructivism should be understood, that is, as focusing upon the dialectics between material reality and mental or conceptual beliefs, how these mutually influence and "construct" one another. The common denominator of both movements is precisely - causality, i.e. how reality is formed by our thoughts about it and vice versa. The problem with at least some modern versions of constructivism is that they too one-sidedly stress mental constructions, making it succumb to mentalism and idealism. 


\section{REFERENCES}

Ahrne, G. (1997). Vad hände på åttiotalet? Sociologisk forskning, no 1-2.

Azevedo, J. (1997). Mapping Reality. Albany: State University of New York Press.

Bhaskar, R. (1989). Reclaiming Reality. London: Verso.

Bhaskar, R. \& Laclau, E. (1998). Discourse theory vs critical realism, Alethia, Vol. 1.

Brante, T. (1989). Anthony Giddens och samhällsvetenskapen. Stehag: Symposion bokförlag.

BRANTE, T. (1994). Teori och typologi. Sociologisk forskning, nr 2.

BARnes, B. (1995). The Elements of Social Theory. London: University College London Press.

Bourdieu, P. (1996). Understanding. Theory, Culture and Society, Vol. 13, No. 2.

Bunge, M. (1973). Method, Model and Matter. Dordrecht: Reidel.

Boudon, R. (1998). Social mechanisms without black boxes. In Hedsröm, P. \& Swedberg, R. (eds).

Cartwright, N. (1983). How the Lawe of Physics Lie. Oxford: Clarendon Press.

Collier, A. (1994). Critical Realism. London: Verso.

Davidson, A. (1997). Foucault and His Interlocurs. Chicago: University of Chicago Press.

Eкsтröm, M. (1994). Residential Relocation, Urban Renewal and the Well-Being of Elderly People. Towards a Realist Approach. Uppsala: Acta Universitatis Upsaliensis.

Engelstad, F. (1996). Norsk sosiologi siden 1969. Tidskrift for samfundsvidenskap, no. 2.

Feyerabend, P. (1993). Against Method, 3:d edition. London: Verso.

Feyerabend, Paul (1995). Killing Time. Chicago: University of Chicago Press.

Foucault, M. (1968). Intervju med Foucault, by Yngve Lindung. BLM.

Gambetta, D. (1998). Concatenations of mechanisms. In Hedsröm, P., Swedberg, R. (eds).

Giddens, A. (1996). In Defence of Sociology. Cambridge: Polity press.

Glymour, C. (1983). Social science and social physics. Behavioral Science, No. 1.

Hacking, I. (1986). Making up people. In Heller, T., Sosna, M., Wellerby, D. (eds). Reconstructing Individualism. Stanford: Stanford University Press.

Harré, R. \& Madden, E. (1975). Causal Powers. Oxford: Basil Blackwell.

Hedström, P. \& Swedberg, R. (1998). Social Mechanisms. Cambridge: Cambridge University Press.

Helgesson, M. (1996). Systemteoretiska modeller. Kropp och själ. Psykosomatik i praktisk sjukvård. Stockholm: Svenska Läkaresällskapet och Spri.

Homans, G. (1964). Bringing men back in. American Sociological Revierw, 29.

Hume, D. (1748/1999). An Enquiry Concerning Human Understanding. Oxford: Oxford University Press.

Johansson, I. (1989). Ontological Investigations. London: Routledge.

Knoke, D. \& Guilarte, M. (1994). Networks in organizational structures and strategies. In Knottrerus, J. \& Prendergast, C. (eds). Current Perspectives in Social Theory. Grreenwich, Conn.: JAI Press.

Lakatos, I. (1970). Falsification and the methodology of scientific research programmes. In Lakatos, I. \& Musgrave, A. (eds) Criticism and the Growth of Knowledge. Cambridge: Cambridge University Press.

Levine, D. (1997). Social theory as a vocation. Perspectives, Vol. 19, No. 2. The American Sociological Association (ASA) Theory Section Newesletter.

Mouzelis, N. (1995). Sociological Theory: What Went Wrong? London: Routledge.

NAsH, R. (1999). What is real and what is realism in sociology? Fournal for the Theory of Social Behaviour, 29: 4.

Popper, K. (1969). The Open Society and Its Enemies, Vol. II. London: Routledge \& Kegan Paul. 
Popper, K. (1990). A World of Propensities. Bristol: Thoemmes.

Rawls, A. (1987). The interaction order sui generis: Goffman's contribution to social theory. Sociological Theory, Vol. 5.

Rorty, R. (1982). Consequences of Pragmatism. Brighton: Harvester Press.

SAYer, A. (1992). Method in Social Science. London: Routledge.

Sayer, A. (2000). Realism and Social Science. London: SAGE.

Schelling, T. (1998). Social mechanisms and social dynamics. In Hedström, P. \& Swedberg, R. (eds).

Searle, J. (1995). The Construction of Social Reality. London: Allen lane.

SEwell, W. (1992). A theory of structure: duality, agency and transformation. American fournal of Sociology, 98.

Smelser, N. (1997). Problematics of Sociology. Berkeley: University of California Press.

Schelling, T. (1998). Social mechanisms and social dynamics. In Hedström, P. \& Swedberg, R. (eds).

Stinchcombe, A. (1991). The conditions of fruitfulness of theorizing about mechanisms in social science. Philosophy of the Social Sciences, Vol 21, No. 3, pp. 367-388.

Stinchaombe, A. (1998). Monopolistic competition as a mechanism. In Hedström, P. \& Swedberg, R. (eds).

Sörenssen, A. (1998). Theoretical mechanisms and the empirical study of social processes. In Hedström, P. \& Swedberg, R. (eds).

Turner, J. (1988). A Theory of Social Interaction. Cambridge: Polity Press.

Wiley, N. (1994). The Semiotic Self. Oxford: Polity Press.

Österberg, D. (1988). Metasociology. Oslo: Norwegian University Press. 